is too small to allow us to find in the sky spectrum all the details observed by Dufay in cometary spectra. Nevertheless, the correspondence between the sky radiations and the first rotational lines of each branch of the band is satisfactory. We find in the sky the $R(3), R(2)$ and $R(1)$ lines at $\lambda \lambda 4291,4295$ and $4299-$ 4303 ; a stronger emission at $\lambda \mathbf{4 3 1 2} \cdot 5$ can be identified with the two $Q$ branches; we find $P(3)$ and $P(4)$ at about $\lambda 4330, P(5)$ at $\lambda 4338$.

When we observe the spectrum of the sky near the horizon, the strong Vegard-Kaplan band of nitrogen at 4316, degraded towards the red, hides the last two CH lines; but, at the zenith, while the whole Vegard-Kaplan system weakens, these lines become very visible; therefore there is something more in this spectral region than a Vegard.Kaplan band.

Since the intensity of the $\mathrm{CH}$ band does not obviously vary from the zenith to the horizon, it is not impossible that the $\mathrm{CH}$ molecules are outside the atmosphere and that a part of the night sky luminescence has an interplanetary or an interstellar origin. It is interesting to recall that Swings has already proposed to identify the $\lambda \mathbf{4 3 0 0}$ interstellar line, observed as an absorption line in stellar spectra, with the $R(1)$ line of interstellar $\mathrm{CH}$ molecules ${ }^{3}$.

Group of lines near $\lambda 4050$. These radiations of cometary nuclei occur also in the sky. Cabannes and Dufay have shown that the lines of the 4050 and 4300 groups correspond to each other with a constant difference of frequency ${ }^{4}$, which is about $1500 \mathrm{~cm} .^{-1}$. In agreement with Baldet's observations, we cannot therefore identify the 4050 band of cometary nuclei and of the night sky with the weak Raffety band which, according to Grenat ${ }^{5}$, is similar to the 3900 band. It is possible that the group at $\lambda 4050$ represents a new $\mathrm{CH}$ band similar to the 4300 band.

Band $\lambda 3900$. The $3800-3900$ region is one of the least known in the spectrum of the sky. Flint prisms are not transparent enough, while quartz prisms do not give sufficient dispersion. On the other hand, the 3889 Vegard-Kaplan band coincides with the $Q$ branches of CH. The $P$ branch only appears distinctly, the $P(2)$ lines at $\lambda 3897$ and the $P(3)$ lines at $\lambda 3902$.

Band $\lambda$ 3143. The very prominent maximum of this band is found in the sky at $\lambda 3144$. We have observed also the weaker maximum at $\lambda 3157$. No other origin has been suggested for these two sky radiations.

Hence we conclude that the known $\mathrm{CH}$ bands probably exist in the spectrum of the night sky. The radiations near $\lambda 4050$ form perhaps a new band similar to the 4300 band and certainly distinct from the Raffety band. The emission occurs at a very high altitude or even outside the atmosphere. We intend to compare again the intensities at the zenith and near the horizon in order to decide whether the emission of the bands that we attribute for the present to $\mathrm{CH}$ molecules is or is not connected with the earth's atmosphere.

Université de Paris and Observatoire de Lyon. Aug. 25.

J. CABANNES.

J. Dufay.

J. GAUZIT.

${ }^{1}$ Cabannes and Dufay, Comptes rendus, 198, 306 (1934); $68^{\mathrm{e}}$ Congrès des Sociétés Savantes, 66 (1935).

${ }^{3}$ Nicolet, M., Z. Astrophys., 15, 154 (1938); Dufay, J., Comptes rendus, 206, 1550 (1938).

'Swings, P., and Rosenfeld, L., Astrophys. J., 86, 486 (1937).

- Cabannes et Dufay, Comptes rendus, 203, 903 (1936).

'Grenat, H., Comptes rendus, 192, 1553 (1931).

\section{Fatty Acids from Yeast as Respiratory Factors}

A NUMBER of papers $^{1}$ from this laboratory have reported the preparation from yeast and maltcombings of fractions which stimulate the respiration of yeast and of animal tissues, particularly of skin. A study of these fractions appears to indicate the existence of a multiplicity of respiratory factors. The fractions studied thus far have been water-soluble and thermostable. They have all contained nitrogen and phosphorus, but the fractions have been manifestly impure and it has been difficult to correlate the respiratory activity with chemical properties except to indicate that protein probably plays no part. On the other hand, it has been possible to correlate the proliferation-promoting activity of preparations from yeast with nucleic acid-like materials containing guanine, adenine, phosphorus and pentoses, and having a maximum in ultra-violet absorption $^{2}$ at $2600 \mathrm{~A}$.

We have now found that the steam-distillation of a crude concentrate prepared by extracting yeast with aqueous alcohol yields about 0.05 per cent (based on the yeast) of a light coloured waterinsoluble substance having an indefinite melting point near room temperature and an unpleasant odour suggestive of isovaleric acid. It does not contain nitrogen or phosphorus. It is soluble in alcohol, ether, benzene, and alkali. It has an iodine number of 5.5 by the Hanus method. The high neutralization equivalent of about 295 is probably accounted for by the presence of contaminating fatsoluble materials. From the steam distillate can be obtained a nearly colourless potassium salt which is unmelted at $300^{\circ} \mathrm{C}$. but darkens at $210^{\circ}$ and dissolves in water to form an alkaline solution. The material gives a negative Liebermann-Burchard reaction. These properties point to a mixture containing saturated fatty acids.

The material causes as much as a 350 per cent increase in oxygen uptake of a yeast suspension in concentrations of $\mathbf{0 . 5} \mathrm{mgm}$. per c.c., but higher concentrations are less effective and $10 \mathrm{mgm}$. per c.c. is inhibitory. In nearly all concentrations, the material is markedly inhibitory to the respiration of rat skin, although in low concentrations ( $1 \mathrm{mgm}$. per c.c.) a slight stimulation is observed. This behaviour is duplicated qualitatively by pure saturated fatty acids such as capric and undecanoic. Thus, the respiratory activity of the distillate appears to be related to its fatty acid content.

The steam distillate, in proper concentrations, markedly stimulates the growth of epithelium in tissue cultures. In the concentrations thus far investigated, the material appears to be inhibitory to yeast growth and fermentation.

A detailed account of this work will appear later.

Euton S. Cook.

Cornelius W. Kreke.

Institutum Divi Thomæ,

Institute of Scientific Research, Cincinnati, Ohio.

Aug. 30.

1 Fardon, Norris, Loofbourow and Ruddy, NATURE, 139, 589 (1937). Norris and Kreke, Studies Inst. Divi Thomo, 1, 137 (1937). Cook, Hart and Joly, Proc. Soc. Exptl. Biol. Med., 38, 169 (1938). Cook, Kreke, and Nutini, Studies Inst. Divi Thomo, in the Press. Cook and Kreke, ibid., in the Press.

Cook, Loofbourow, and Stimson, 10th International Congress of Chemistry, Rome, May, 1938. Loofbourow, Cook, and Stimson, in the Press. 